This is a post-peer-review, pre-copyedit version of an article published in Higher Education Policy. The definitive publisher-authenticated version Eigi, Jaana; Pille Põiklik, Endla Lõhkivi and Katrin Velbaum (2014). Supervision and Early Career Work Experiences of Estonian Humanities Researchers Under the Conditions of Project-based Funding. Higher Education Policy 27(4), 453468, https://doi.org/10.1057/hep.2014.21

is available online at: https://link.springer.com/article/10.1057/hep.2014.21

\title{
Supervision and Early Career Work Experiences of Estonian Humanities Researchers under the Conditions of Project-based Funding
}

Jaana Eigi, University of Tartu, jaana.eigi@ut.ee

Pille Põiklik, University of Tartu, pille.poiklik@ut.ee

Endla Lõhkivi, University of Tartu, endla.lohkivi@ut.ee

Katrin Velbaum, University of Tartu, katrin.velbaum@ut.ee

\begin{abstract}
We analyze a series of interviews with Estonian humanities researchers to explore topics related to the beginning of academic careers and the relationships with supervisors and mentors. We show how researchers strive to have meaningful relationships and produce what they consider quality research in the conditions of a system that is very strongly oriented towards internationalization and project-based funding, where their efforts are compromised by a lack of policies helping them establish a stable position in academia. Leaving researchers to face these obstacles alone places a great burden on them and may lead to a loss of talent in academia. Identifying and addressing these issues is thus important for both the well-being of early career researchers and the future of academia.
\end{abstract}

Key words: careers, funding, job security, humanities, values, supervisor-supervisee relationship 


\section{Introduction}

The aim of the paper is to explore the early career experiences of Estonian humanities researchers under the conditions of a higher education and research system that has undergone dramatic changes over the last two decades. One of the most significant consequences of these changes is the remarkably large share of project-based funding in the Estonian research system.

There is dual motivation behind this aim. First, the paper is part of an ongoing project analyzing scientific cultures in Estonia. It was inspired by UPGEM (Understanding Puzzles in the Gendered European Map), an international investigation of the gendered patterns of staying in or leaving academia among European physicists (Hasse et al., 2008a; Hasse et al., 2008b; Hasse and Trentemøller, 2008). Two of the authors-Endla Lõhkivi and Katrin Velbaum-represented Estonia in the project. In the UPGEM interviews, physicists frequently made references to and comparisons with the humanities. Through this, our research group was led to investigate the work culture in the humanities. For the past three years, we have been exploring the epistemic impact of work practices and the relationship between current evaluation practices and researchers' aims and values. As shown by Lõhkivi et al. (2012), they may have serious epistemic consequences for the quality and credibility of the knowledge humanities produce. In this paper, we approach the data from a new angle and focus on the impact of the conditions of Estonian higher education and research system on early career researchers' supervision and work experiences and perspectives of a career in academia (following Bazeley, 2003, we prefer the term "early career researcher" to "young" researcher since different educational and career trajectories mean that people reach this stage at different ages). This, in turn, has far-reaching implications as it may influence the chances of academia retaining researchers and, through that, ensuring its future. 
The second motivation for this article is to contribute to the discussion of the situation of early career researchers, a topic that has attracted international attention (e.g., Frischer and Larsson, 2000; Fox and Stephan, 2001; Austin, 2002; Bazeley, 2003; Nerad, 2004; Akerlind, 2005; Laudel and Gläser, 2008; Brew et al., 2011). We believe that the case of a small country like Estonia is a convenient example for studying the consequences of implementing a system with a very large share of project-based research funding, since changes in higher education and research funding policy can be made swiftly and comprehensively here and their consequences also likely to become apparent faster than they would in larger systems with a greater resistance to change.

\section{Data and method}

While the project was inspired by the data on physicists, in the current paper, we use only the interviews with humanities scholars conducted as part of our own project. Thus, the paper is based on 23 semi-structured interviews conducted in 2010-2012. In 2010, five pilot interviews were made with researchers currently working in different fields in the humanities. We used a slightly modified version of the UPGEM questionnaire (see Hasse et al., 2008a, 375-380 for the original questionnaire). The modifications served to make it more suitable for humanities researchers; otherwise, the overall structure of the interviews was preserved.

From the pilot interviews, it became clear that, in order to have a manageable set of data, it was important to restrict our inquiry to one discipline, and we chose the field of history. We do not assume history to be the model discipline for humanities (as physics was for natural sciences); instead, it was chosen as a discipline with a relatively strong position and clear discipline borders in Estonian academia. In order to include both "leavers" and "stayers", in 2011, ten interviews were made with active historians and, in 2012, eight interviews were made with those who had started their $\mathrm{PhD}$ studies but subsequently left either academia in general or the discipline of history in particular. In choosing the 
respondents, we tried to maintain gender balance: 12 interviews were conducted with females and 11 with males. We also wanted the interviews to cover different levels of academic career and, thus, among respondents were $\mathrm{PhD}$ students, research fellows and senior research fellows, associate and full professors. The respondents were between 31 and 77 years of age. With each interviewee, an approximately hour long interview was conducted. The interviews were transcribed verbatim and, for the sake of anonymity, all personal and geographical names as well as the names of the institutions were coded.

Our method of analysis was qualitative in nature and followed the basic tenets of grounded theory (Strauss and Corbin, 1994; Charmaz, 2006). We were interested in the emergent categories in our data and, in that sense, let our analysis be data-driven. Our initial readings of the data led us to focus on the most salient categories and choose the topics related to the interviewees' supervision and mentoring relationships and their early career narratives. We were interested in the values that the interviewees prefer to follow in their research and the obstacles in doing this, with a particular focus on the influence of the projectbased research system on newcomers' experiences.

\section{Estonian higher education and research system: changes, internationalization and project funding}

After Estonia regained its independence in 1991, its system of higher education and research funding has undergone significant changes. As in other Central and Eastern European (CEE) countries after the collapse of the Soviet Union, introduction of quality assessment and competition in the distribution of funding has been among the guiding principles for the change (Radosevic and Lepori, 2009), together with internationalization of the higher education and research systems. 
As part of the internationalization process, the Estonian system of higher education has been adapted to the emerging European framework: Estonia switched to the $3+2$ system in higher education in accordance with the Bologna process as early as 2002/2003, just three years after the process began (see Curaj et al., 2012 and Tina, 2008 on implementing the Bologna process in Estonia; an overview of the current higher education system in Estonia is given in Higher Education System [in Estonia], 2013 and Vaht et al., 2010).

The Estonian research and development system was similarly reoriented towards becoming part of the international system. The importance of international integration can be judged by the fact that a considerable part of public research funding in Estonia $(18.6 \%$ in 2011) comes from foreign sources (Estonian Research and Development and Innovation Strategy 2007-2013 “Knowledge-based Estonia” Report, 9). Internationalization is also reflected in students and academic staff being actively encouraged to go abroad, with numerous funding sources, organizations and international agreements to support it (see Rannala, 2009, 33 for a brief overview). Several strategy documents (Standard of Higher Education; Strategy for the Internationalization of Estonian higher education 2006-2015) require additional training abroad, and there are different mobility programs for researchers and teaching staff. Also, as a continuation of existing mobility trends among students, the goal is to ensure that, by 2015 , all doctoral students who defend their theses at Estonian universities have spent at least a semester abroad.

These changes could not but have a profound effect on people receiving their education during the years of change, just as they affected established researchers who were their supervisors. However, an even more profound influence that continues to define one's experience in Estonian academia has been brought on by the changes in the public research funding system. Radosevic and Lepori $(2009,661)$ characterize the initial state of public 
funding systems in CEE countries as dominated by institutional funding, with project funding gradually gaining a greater importance and a greater variety of forms. In Estonia, however, this process has relatively quickly led to the dominance of project-based funding to a degree unmatched not only in many CEE countries but also in many Western European ones.

As Lepori et al. $(2009,673)$ summarize the Estonian situation, project-based funding constitutes a very large part of public research funding — over three quarters of the total—and there is a considerable number of instruments for distributing it. At the same time, the extent of institutional funding is small and the number of instruments for it is also very limited. They date the shift in the Estonian funding system to 1997-1998, and the data presented by Masso and Ukrainski $(2009,688)$ make the scale of the shift visible: in 1997, project-based funding constituted $41 \%$ of the total public funding; in 1998 , its share jumped to $83 \%$. To put these numbers in perspective: according to the analysis of public research funding in six Western European countries by Lepori et al. (2007), project funding is an important (from about a quarter to a third of total funding) but not the dominant form of funding in those countries.

While an increasing share of project funding has been a feature of research funding systems worldwide, the extent to which it has been taken in Estonia is characterized by a number of problems. One of the consequences of the large number of project funding instruments is what Raudla et al. (2014, 20-24) discuss as the fragmentation of funding sources. Many of the Estonian researchers in natural sciences that Raudla et al. (2014) interviewed said that at any given moment a research group is typically relying on five-six different grants, often more, as a single grant is usually not sufficient to sustain research. The need to apply for numerous grants that often have different requirements brings with it a burden of administrative duties, which leaves less time for research. Another problem Raudla et al. (2014, 24-27) identify is fluctuations in available funding, as different funding sources 
have project funding of different durations (the longest projects are up to six years but many are considerably shorter, sometimes under six months). Usually, they are not coordinated with each other and neither is the duration of a project coordinated with the duration of researchers' work contracts with their institutions (or with the duration of doctoral and postdoctoral studies). Interruptions in funding are thus likely and long-term research planning, keeping research group members employed and supporting doctoral students are difficult. As a result, the quality of research suffers (for an analysis of the mechanisms of this negative influence, see Laudel, 2006). ${ }^{\mathrm{i}}$

Additionally, there are problems in the Estonian project-based system that are specific to humanities and social sciences. As Masso and Ukrainski (2009, 692-693) note, the share of funding allocated to them is relatively low. The assessment procedures associated with funding allocation mostly rely on peer-reviewed papers as a measure of productivity and quality and, thus, place areas where monographs are an important form of output at a disadvantage. As a result, quality assessment further reinforces the concentration of funding in the exact sciences.

In order to understand the context of our interviews, it is thus necessary to keep in mind that, in less than twenty years, a system has emerged that not only differs profoundly from the higher education and research system in the Soviet Estonia but is also unusual in comparison with many European countries due to the very large share of project-based funding. These changes have influenced all aspects of academic life in Estonia. In this paper, we are interested in the effect of project-based funding on mentoring and supervision (most researchers in Estonian universities also teach and supervise) and on the beginning of the academic career. In particular, we are concerned with the potential mismatch between the policy of encouraging international mobility of early career researchers and the project-based 
funding system that usually does not allow keeping a position in Estonia open during a stay abroad. Since most of our interviewees work in areas connected with the Estonian context (Estonian history, language and literature studies, ethnography) and see contributing to the Estonian culture as an important aim of their work (Lõhkivi et al., 2012) being able to have a stable connection with Estonian academia is crucially important for them. On a more general level, their experience can be seen to reflect the inherent tensions between the different aims in the Estonian system: simultaneously with internationalization, the aim of preserving and developing Estonian language and culture has remained an important part of Estonian strategies, lately reaffirmed in the Estonian RD\&I strategy "Knowledge Based Estonia 20142020".

\section{Patterns of supervising and mentoring}

As we started to investigate the interviewees' experiences, we were, among other things, interested in exploring the values that underlie their actions as researchers in the Estonian humanities. The interviewees' values help define their identities as members of research communities, affect their choice of supervisors and mentors, and greatly shape the choices made in early careers. A number of characteristics emerged as the core values, among them erudition, reading oneself into the field, being well-informed of current research while also being able to hold a broad dialogue, and being thorough in one's work. The interviewees' focus on such research-related values points to "what the group wishes to include and what it excludes" (Traweek, 1988, 93). What we noticed was a lack of discussion-not to mention appreciation—of values related to successfully surviving in the project-based system.

The data suggests that the preferred group identity is centered on doing research not for formal results but for the sake of research itself. This, for example, leads the interviewees to prioritize the ability to write well over the ability to write a significant volume: 
M4: What is certain is that I want to be very professional in my work. So _ so the idea might be that I don't _ don't write a single article just to meet some criteria. I want to spend a lot of time on a single piece _ to be the primary critic of my own work. /.../ I don't want to submit anything casually, or I don't want to write a single trivial paper.

Such values are positioned in an uneasy opposition with some of the realities of the academic world in Estonia that has been increasingly relying on fixed-term research grants and contracts, creating a system in which the prerequisite of success is the ability to produce measurable research at an ever-increasing pace.

Interestingly, the interviewees often do not oppose the project-based system completely. When Estonia began to have closer contacts with the West, it was possible to make comparisons between the different systems and many interviewees positively recall their experience of the supervision and mentoring received abroad:

F5: And then you saw how students are directly involved in projects, you get a sense of perspective. That this _ what I'm doing, that other people have an interest in it, and also that I can really have a dialogue with someone and work within a framework.

Projects that supervisees and students could be included in are a more recent development in Estonia:

F5: I think it was actually a different time. No one even really tried to involve students in research in any way. I have often compared that to our situation now when we frequently search for students everywhere, whom we could include in our project at first as MA students, later as doctoral students. In hindsight, it seems to be a huge 
waste. But, well, back then of course there were none of these research projects in such a format. There was no need for it.

This refers to two different modes of existence. The previous system had no direct need for including students, whereas the new one would involve students in the hope of raising a new generation of researchers and out of the need to staff different research projects. The new generation would have to play by a different set of rules from the previous one and this has led to changes in the process of people maturing as researchers.

In the system of fixed-term contracts and constant applying for funds, providing a sense of security and stability to newcomers can, however, be a challenge for supervisors and mentors, as they most often lack these things themselves. Their ability to help students may be limited, and their motivation to contribute to students' development undermined:

M2: The policy of Estonian Research Council was that everyone received a third [of the funding requested], which meant that, that, well, the plan _ fulfilling the plan was quite difficult. Well, actually, impossible; fulfilling the plan in full.

M1: Job security? _ No, definitely not. A 5-year contract for a professor, that is not normal. So _ by [my] age I have reached a clear understanding of, for example, how long a project takes. And usually it is, a minimum project, if you want to reach any results at all, it's about 8 years. You will, of course, get results on the side, but that, that you have untangled a knot _ about 8 years. And this means that as a professor it is practically impossible to start _ something really serious. It's possible to finish something. That's absurd. 
Fixed-term contracts up to five years are in fact the norm for an academic position in Estonia; there are no permanent contracts with the exception of the contract "for an unspecified term" that can be made with a person who has worked as a professor at the same university for at least 11 years (i.e., has had the contract renewed at least twice) ((Universities Act, §39(1) and $\left.\S 39^{1}(2)\right)$. There is no tenure. The frustration of the interviewee suggests that even the highest and presumably most stable positions in Estonian academia are little more than temporary and do not provide enough stability to undertake long-term projects. This makes it more difficult to offer stability to people in the early stages of their careers. As F5 notes: "In our institution, it is very clear that salaries come from there, since money for teaching keeps getting smaller /.../. If there's no project, you cannot hire anyone“.

The position that supervisors are in might help explain some of the patterns that emerge in the supervision and mentoring relationships. When asked about their supervisors, the interviewees distinguish between two categories of supervisors: one labeled with the adjective "formal" and the other with "content-related" (the Estonian word they use for the latter is sisuline which suggest that these supervisors are specifically focused on the substance of the interviewees' research). Different interviewees attach different interpretations to these terms but, overall, it can be concluded that content-related supervisors are considered actual supervisors, whereas formal ones are not as appreciated:

M2: We had _ meaningful collaboration with [Lecturer1] from before; [Lecturer2] was _ was, like, this formal supervisor. And [Lecturer2] was _ was - to a great extent, he devoted his supervision to this _ let's say, like, formal and methodological aspect. And with [Lecturer1] I already had a fairly good rapport in _ solving these content-related problems. 
Thus, having a content-related supervisor means that the supervisor devotes considerable time and energy to the supervisee. Formal supervisors might provide letters of recommendation or serve other bureaucratic functions but fall short in other senses. A perceived lack of cooperation can lead to feelings of disappointment and frustration often born of the supervisees' values standing in contradiction to the type of assistance offered. Thus, if supervisees value doing what they consider meaningful research, supervisors attempting to bring them into a project-based system might remain underappreciated, if not outright criticized.

The interviewees can struggle greatly when the academic reality does not live up to the values they associate with meaningful quality work. In the end, however, they are judged on the basis of formal criteria, and time spent on certain projects "must be transformed into academic capital—publications, teaching and administrative responsibilities, and ultimately permanent roles" (Garforth and Červinková, 2009, 182). The opposition of preferred values and formal requirements echoes the value conflict identified among Estonian humanities researchers by Lõhkivi et al. $(2012,129)$ who point out how, "for the sake of fundraising, [they are] forced to fulfill formal scientometric evaluation criteria by producing easily trackable short-format articles which are endorsed neither by the humanities community nor the wider society". The values the interviewees relate to are "deeply inscribed in the identities and performances of researchers' academic selves" (Garforth and Červinková, 2009, 171). In the situation of a value conflict, these preferred values can make researchers deviate from the paths that might lead to a more successful career and, for example, seek supervisors who match these values rather than those who would focus on their success in the project-based environment. 


\section{Early careers}

The discussion of supervision in the interviews shows the contrast between meaningful and formal supervision and the tension between the preferred values and the project-based environment, and similar tensions characterize the discussion of early careers. Interviewees emphasize research and teaching rather than advancing in the ranks or scoring highly in formal assessments; and this shapes the stories they tell. In particular, a recurring theme is a graduate, low-key beginning through small tasks and part-time appointments while the interviewees were still studying. Being in academia is described through meaningful work rather than through moving along formal milestones, such as the graduation followed by signing the work contract.

M2: Before graduation, I already began, began to work. /.../ Graduation didn't bring any great changes. /.../ Well, the reasons were very simple: there was no money and I had to find a way to get it, and, and then it was possible to join a research branch at [an academic institution different from M2's university]. So this _ [institution] paid me a salary to write and finish my BA thesis.

At least two interviewees recall beginning to work at university without pay until some funds were found. In their interviews, the change of status from an unpaid to paid worker is not described as changing the meaning of their work; not being paid did not render it meaningless.

However, the conviction that some opening would be found and the low-key beginning would eventually lead to a more stable position becomes increasingly problematic. In order to do research, one needs a connection with academia and funding which in the project-based system depends on newcomers being able to establish themselves as capable of 
competing for grants and positions. As an early career researcher, one has to change from doing what one is asked to do to pursuing one's own line of research. Laudel and Gläser (2008) describe this period as the most important change of status for a researcher: from dependent to independent research, from an apprentice to a colleague who plans research autonomously. They suggest that after receiving the $\mathrm{PhD}$ degree, the most important factor for a successful transition is the "research-intensive phase" (Laudel and Gläser, 2008, 401) before taking on a full teaching and administrative load (Bazeley, 2003, 274 makes a similar point when he stresses the importance of "uninterrupted, stable research development" after the completion of studies). Otherwise, early career researchers may not be able to establish a basis of published research.

The interviewees' answers suggest that, although joining academia in some minimal sense is not necessarily difficult, achieving a position that would allow such a researchintensive period is. Entering the "outer circle" of temporary and part-time employment is easy; joining the "inner circle" where employment is more stable is a serious challenge. The strongly project-based funding system in the Estonian humanities puts all researchers in the position that Fuchs (1992) described as typical for highly competitive natural sciences. Fuchs (1992, 154-155) points out that resource-demanding fields (such as experimental research in natural sciences) are similar to professions with strict "entry restrictions": the competition for resources is fierce and it is not easy to become a member of a cutting-edge research group that has secured access to them. Humanities and social sciences, on the other hand, do not require the same amount of high-cost resources; researchers can obtain them from various sources and thus enter the profession more easily. With the current funding policy and research organization in Estonia, however, the competition for funding is very intense even if the distributed sums are modest. In humanities, the situation is further exacerbated by the fact that their share of funding is low and the assessment criteria are not always suitable for their 
research output. This means that, in Estonia, researchers in "cheap" humanities face intensive competition similarly to researchers in "expensive" experimental sciences.

As the earlier quote from M1 shows, even the professor position does not bring complete security. Academic staff depends on continuing to receive grants and to have contracts renewed and thus faces constant uncertainty.

F8: Well, I want to stress once again that, for me, for me research has been a hobby, but if you happen to be a research fellow, you have fixed term _ contracts, you have to compete for this _ grant. It is highly probable that, most of the time, particularly in humanities, there is that background knowledge whether you will get the grant or not; it's highly likely that you won't. So, there's quite a lot of uncertainty for namely those in a research fellow position.

Another interviewee characterized former colleagues as permanently "terribly scared" about what is going to happen to them after a grant ends.

For an early career researcher, this situation is even more difficult as one often faces a Catch-22 situation: in order to compete successfully for a grant, one needs a history of doing outstanding research that is, in turn, impossible without a grant. An early career researcher, thus, often depends on a more established colleague who is more likely to secure a grant. This requires maintaining connections, being visible to supervisors and available when an assistant for a project is needed. If one's connections with community weaken, acquiring a position may be difficult, if not impossible.

For this reason, spending time abroad that has been strongly encouraged in Estonian academia (and most of the interviewees have spent some time abroad) often weakens the possibility of continuous development of an academic career at home. Former supervisors are 
usually unable to keep a position open for absentees, since funding mostly comes from shortterm grants and the project one was previously working on is likely to have ended in the meanwhile. According to one of the interviewees, one of the reasons to apply to a $\mathrm{PhD}$ program in Estonia, despite already holding an equivalent degree of the Candidate of Sciences, was the conviction that she could not find a job after returning (another reason in her case was the obscurity of the Soviet system of degrees in the West).

There was a brief period during the early stage of Estonian reforms when a stay abroad needed not be an impediment to a career at home. On the contrary, during the period of initial changes, when the system that had turned towards internationalization was searching for candidates with internationally recognized credentials, someone returning with a $\mathrm{PhD}$ degree at the right moment could be welcomed to an academic position. One interviewee admits that he was exceptionally lucky in this respect:

M7: It somehow went really well for me. I belong to the right age group, as they say. So, when the society changed, I was just, ready to get the $\mathrm{PhD}$ and then immediately went abroad precisely in that age and, let's say, I think that for those older than me, it was difficult for them maybe simply because of foreign languages. And again those who were younger, for them the difficulty was that the other generation was in front of them.

A similar opening may be made possible by more local changes, like the establishment of new institutions or the merging and reorganization of existing ones:

F5: When I defended an MA in history in [Institute1] of [University1], we opened [Research Centre1 at the University1] and it created the possibility that I could get a 
job at the university. Because, before that, I didn't feel like I could get a job at an Estonian university at all, especially at the history department of [another Estonian university] where there are simply no positions, I think, to this day.

However, such unpredictable changes are not something upon which one can realistically base return plans. Accordingly, one finds oneself in the situation where openings that existed during the period of most rapid changes and strongly incentivized going abroad are no longer available, while the encouragement of PhD student stays abroad continues.

The remaining opportunity for someone returning from abroad is to be included in a grant application made by someone in a more stable position in Estonia:

F3: I owe a debt of gratitude to [Name1] who took me on as an adjunct researcher and, and, and the reason was that I was, I think since 2002, we were on the same grant. I mean, [Name1] was the principal researcher but we both with [Name2] helped write and create it. /.../ So, in this sense, this grant helped me to get established in Estonia.

Similarly to the returns from abroad that luckily coincided with the major reforms, researchers returning from abroad when the new grant system was first established won most from this opportunity. Someone with publications and experience from abroad was a highly desirable presence in a grant application. As one of the interviewees recalls:

F2: I was at that time at [Institute1], when the first grants were announced and, because of that, they really wanted me back. At that time, the first people were starting to return from abroad. /.../ I was the first to come back, after that there was a cascade or returns. 
Although this eager anticipation has subsided, someone with a PhD degree, publications and a willingness to work on a short-term grant project may still be welcomed to contribute to local grants if a researcher is needed.

F9: Um, I returned in a really strange way, that is, professor [Name4] called me and asked, that, said he was preparing a grant application and asked whether I wanted to take part in it. /.../ [Name4] made his grant application at the time, well, professor [Name4] made it at the time when it was relatively difficult to find unengaged people with a $\mathrm{PhD}$ degree because, um, I must say, there's no unemployment for historians with a $\mathrm{PhD}$, there are all kinds of places, so that, that, um, evidently these grants are considered relatively insecure, it's more secure to work in an archive or, or, museum.

An extreme case of this is described by F3: a researcher returned to Estonia on a European mobility grant and needed it supplemented by a local source, so he proposed to publish his forthcoming papers as part of any local project in return for the funding. In this case, it is not even the researcher as workforce in the project that is needed but rather publications to include in reports associated with it.

F3: Well, there was a great moment when [Name2] convinced [Name6] that; he went there and put a pile of papers that were about to be published on [Name6's] desk and said "See these publications, could they be useful for some grant or something? I'm ready to contribute and, in return, I'd like to have a place, so to say". 
Although joining a local project currently provides a way to return, it can be frustrating if the people formally united by a grant proposal do not actually have shared research interests, rendering meaningful collaboration impossible. Uncertainty of employment and dependence on short-term funding threatens the possibility of developing one's research, instead making researchers adapt to the next grant proposal or change the research topic as their position changes. In a way, this dependence on someone else's grants continues the dependence early career researchers face in the "outer circle" of employment working on casual tasks and doing whatever is needed by the institution.

\section{Discussion and conclusion}

Our interviews reveal that Estonian humanities researchers' core values sit in an uncomfortable opposition with many of the requirements of the project-based research environment. Reflecting those values, the main search is, for them, about meaningful relationships (as opposed to formal bureaucratic connections) and producing meaningful quality work (as opposed to satisfying formal criteria). This observation coincides with Austin's (2002, 107) findings among American doctoral students: "Although historically faculty work has been seen as a "calling" /.../, this term does not characterize our respondents. Instead, prospective faculty members today want "meaning" in their work. They want to engage in work that has a positive impact on the students with whom they come in contact or on the broader society and work that has personal significance for them".

On the basis of the interviews, we identify several obstacles to this search that are related to short-term project-based funding of research positions. First, early career positions are usually temporary and ad hoc, serving the teaching needs of the institution or the research interests of the grant holder rather than helping researchers' long-term professional development. Accordingly, their chances of establishing themselves as independent researchers who are capable of successfully applying for grants are low. This is the problem 
Laudel and Gläser (2008) point out. Second, dependence on short-term grants means that absence, including studies abroad, can interrupt the connection with Estonian academia and, upon return, bring the early career researcher back to dependence on someone else's grants. The dependence of academia on short-term grants influences early career researchers in yet another way, this time indirectly. Their supervisors also depend on grants, often small ones, and, thus, can only help them with temporary and part-time positions. Accommodating researchers with a $\mathrm{PhD}$ degree and foreign experience whose production the current policy system encourages is not well realized in the system.

One may acknowledge these difficulties and yet suggest that they do not constitute a problem. These obstacles can be seen as part of the selection mechanism, as the possibility to check whether early career researchers are able to establish themselves without help. Traweek (1988) describes how such expectations can be built into the functioning of a highly prestigious and competitive field on the example of high-energy physics (as we point out on the basis of Fuchs's account, in the Estonian academic market even presumably cheaper humanities have to face intense competition). As Traweek shows, early career researchers are expected to do independent and risky work without being told so. Instead, they are expected to "leap over obstacles" (Traweek, 1988, 88), to see through opaque messages and understand that the behavior that leads to success in the system is not the same that the system officially endorses.

Even if the lack of support can be seen as a selection mechanism, our interviews show that its cost is high, both at the level of the individual and the system, and the frustration caused by the obstacles to doing meaningful work permeates every aspect of academic life. Ultimately, it may result in driving qualified researchers away from academia. The lack of a support system in this case produces a waste of resources, given what has already gone into educating newcomers up to that point. Dedicating some of these resources to helping early 
career researchers seems both financially rational (preventing the loss of talent and the associated loss of educational investment) and fair to the early career researchers who currently have to carry the burden of poor organization. A part of this support could go towards communicating future career paths to newcomers more explicitly, helping them better adapt to the formal demands of academia and providing them with the kind of meaningful support they expect from academic encounters. In so doing, it might be possible to bridge the gap between the preferred role of a traditional researcher and the frequently rejected role of a successful agent in the project-based academic world.

i In 2012, institutional research funding and personal research funding, two new instruments combining institutional and project-based elements, were introduced in Estonia with the aim (among others) of decreasing fragmentation and improving coordination between funding sources by replacing several of the previously existing funding instruments. As our interviews were mostly conducted before their introduction, we do not discuss them in the article. It is not yet clear whether they will be able to solve the problems discussed. For example, Raudla et al. (2014, 2, 16 and 24) point out that they may exacerbate the problem of funding fluctuations for groups that fail to secure institutional research funding during a given year's application round. The number of failed applications is considerable: in 2014, the failure rate of institutional research funding applications was $40 \%$ overall and $52 \%$ for the humanities and social sciences (Estonian Research Council's Memorandum, 2014, 1); for personal research funding applications, the overall failure rate was $87 \%$ (Estonian Research Council's Memorandum, 2014, 8). 


\section{References}

Akerlind, G.S. (2005) 'Postdoctoral researchers: roles, functions and career prospects', Higher Education Research \& Development 24(1): 21-40.

Austin, A.E. (2002) 'Preparing the next generation of faculty: graduate school as socialization to the academic career', The Journal of Higher Education 73(1): 94-122.

Bazeley, P. (2003) 'Defining “early career” in research', Higher Education 45: 257-279.

Brew, A., Boud, D. and Namgung, S.U. (2011) 'Influences on the formation of academics: the role of the doctorate and structured development opportunities', Studies in Continuing Education 33(1): 51-66.

Charmaz, K. (2006) Constructing Grounded Theory. A Practical Guide Through Qualitative Analysis, London: Sage Publications.

Curaj, A., Scott, P., Vlasceanu, L. and Wilson, L. (eds.) (2012) European Higher Education at the Crossroads: Between the Bologna Process and National Reforms, Dordrecht: Springer.

Estonian Research and Development and Innovation Strategy 2007-2013 "Knowledge Based Estonia”. Report on achieving the objectives and implementing the strategy in 2012.

Available at: http://www.hm.ee/index.php?popup=download\&id=12338, accessed 1.05 .2014

Estonian Research and Development and Innovation Strategy 2014-2020 “Knowledge Based Estonia”. Available at: http://www.hm.ee/index.php?0513298 (in Estonian), accessed 1.05.2014.

Estonian Research Council's Memorandum on the year 2014 Application Round for Institutional Research Funding, Core Infrastructure Funding and Personal Research Funding. Available at: 
http://www.etag.ee/wp-content/uploads/2014/03/IUT_PUT-m\%C3\%A4rgukiri.pdf (in Estonian), accessed 14.05.2014.

Fox, M.F. and Stephan, P.E. (2001) 'Careers of young scientists: preferences, prospects and realities by gender and field', Social Studies of Science 31(1): 109-122.

Frischer, J. and Larsson, K. (2000) 'Laissez-faire in research education — an inquiry into a Swedish doctoral program', Higher Education Policy 13: 131-155.

Fuchs, S. (1992) The Professional Quest for Truth: A Social Theory of Science and Knowledge, Albany: State University of New York Press.

Garforth, L. and Červinková, A. (2009) 'Times and Trajectories in Academic Knowledge Production', in U. Felt (ed.), Knowing and Living in Academic Research: Convergence and heterogeneity in research cultures in the European Context, Prague: Institute of the Sociology of the Academy of Sciences of the Czech Republic, pp. 169-224.

Hasse, C., Sinding, A.B. and Trentemøller, S. (eds.) (2008a) Draw the Line! Universities as Workplaces for Male and Female Researchers in Europe, Tartu: Tartu University Press. Available at: http://cordis.europa.eu/documents/documentlibrary/116810481EN6.pdf, accessed 1.05.2014.

Hasse, C., Trentemøller, S. and Sinding, A.B. (eds.) (2008b) Draw the Line! International Conference, Copenhagen 2008. Papers, proceedings and recommendations, Tartu: UPGEM. Available at: http://cordis.europa.eu/documents/documentlibrary/116810471EN6.pdf, accessed 1.05.2014. 
Hasse, C. and Trentemøller, S. (2008) Break the Pattern! A Critical Enquiry into Three Scientific Workplace Cultures: Hercules, Caretakers and Worker Bees, Tartu: UPGEM. Available at:

http://cordis.europa.eu/documents/documentlibrary/116810421EN6.pdf, accessed 1.05 .2014

Higher Education System [in Estonia], 2013. Available at: http://www.hm.ee/index.php?popup=download\&id=12349, accessed 30.11.2013.

Laudel, G. (2006) 'The art of getting funded: how scientists adapt to their funding conditions', Science and Public Policy 33(7): 489-504.

Laudel, G. and Gläser, J. (2008) 'From apprentice to colleague: the metamorphosis of early career researchers', Higher Education 55: 387-406.

Lepori, B.; van den Besselaar, P.; Dinges, M.; Potì, B.; Reale, E.; Slipersæter, S.; Thèves, J. and van der Meulen, B. (2007) 'Comparing the evolution of national research policies: what patterns of change?', Science and Public Policy 34(6): 372-388.

Lepori, B.; Masso, J.; Jablecka, J.; Sima, K. and Ukrainski, K. (2009) 'Comparing the organization of public research funding in Central and Eastern European countries', Science and Public Policy 36(9): 667-681.

Lõhkivi, E., Velbaum, K. and Eigi, J. (2012) 'Epistemic injustice in research evaluation: a cultural analysis of the humanities and physics in Estonia', Studia Philosophica Estonica 5(2): 108-132.

Masso, J. and Ukrainski, K. (2009) 'Competition for public project funding in a small research system: the case of Estonia', Science and Public Policy 36(9): 683-695.

Nerad, M. (2004) 'The PhD in the US: criticisms, facts, and remedies', Higher Education Policy 17: 183-199.

Radosevic, S. and Lepori, B. (2009) 'Public research funding systems in Central 
and Eastern Europe: between excellence and relevance: introduction to special section', Science and Public Policy 36(9): 659-666.

Rannala, R. (2009). ERAWATCH Country Report 2009: Analysis of policy mixes to foster R\&D investment and to contribute to the ERA. Estonia. Luxembourg: Office for Official Publications of the European Communities. Available at:

http://erawatch.jrc.ec.europa.eu/erawatch/opencms/information/reports/countries/ee/rep ort_mig_0001, accessed 4.05.2014.

Raudla, R., Karo, E., Kattel, R. and Valdmaa, K. (2014). Detsentraliseeritud konkurentsipõhise teadusrahastuse mõju finantsjuhtimisele Eesti ülikoolides. TIPS poliitikaanalüüs.

Available at:

http://www.tips.ut.ee/index.php?module=32\&op=1\&id=3657 (in Estonian), accessed 1.05 .2014

Standard of Higher Education. Government of the Republic Regulation No 178 of 18 December 2008, RT I 2008, 57, 322 (entry into force 01.01.2009). Available at: https://www.riigiteataja.ee/akt_seosed.html?id=129102013009\&vsty=TOLK, accessed 18.05.2014.

Strategy for the Internationalization of Estonian Higher Education 2006-2015. Available at: http://www.hm.ee/index.php?03236 (in Estonian), accessed 30.11.2013.

Strauss, A. and Corbin, J. (1994) 'Grounded theory methodology. An overview', in N. K. Denzin and Y. S. Lincoln (eds.), Handbook of Qualitative Research, Thousand Oaks: Sage Publications, pp. 273-285.

Tina, A. (2008) 'Kahetsükliline kõrgharidus ehk 3+2 süsteem', in A. Valk (ed.), Bologna 
protsess Eestis 2004-2008, SA Archimedes, pp. 13-17. Available at: http://www.hm.ee/index.php?popup=download\&id=8966 (in Estonian), accessed 1.05.2014.

Traweek, S. (1988) Beamtimes and Lifetimes. The World of High Energy Physicists, Cambridge and London: Harvard University Press.

Universities Act, RT I, 13.03.2014, 77. Available at: https://www.riigiteataja.ee/en/eli/521032014002/consolide, accessed 15.05.2014.

Vaht, G., Tüür, L. and Kulasalu, Ü. (2010) Higher Education in Estonia. Fourth Edition, Archimedes Foundation. Available at:

http://www2.archimedes.ee/enic/File/Higher_Education_in_Estonia_2010.pdf, accessed 1.05.2014. 